\title{
Metabolic Syndrome and DNA Damage: The Interplay of Environmental and Lifestyle Factors in the Development of Metabolic Dysfunction
}

\author{
Giuseppe Potrick Stefani1,2*, Giovana Baldissera ${ }^{3}$, Ramiro Barcos Nunes', \\ Thiago Gomes Heck ${ }^{4,5}$, Cláudia Ramos Rhoden ${ }^{2,6}$ \\ ${ }^{1}$ Laboratory of Physiology, Universidade Federal de Ciências da Saúde de Porto Alegre, Porto Alegre, Brazil \\ ${ }^{2}$ Laboratory of Oxidative Stress and Atmospheric Pollution, Universidade Federal de Ciências da Saúde de Porto \\ Alegre, Porto Alegre, Brazil \\ ${ }^{3}$ Laboratory of Toxicological Genetics, Universidade Federal de Ciências da Saúde de Porto Alegre, Porto Alegre, \\ Brazil \\ ${ }^{4}$ Research Group in Physiology, Regional University of Northwestern State's Rio Grande do Sul (UNIJUI), Ijuí, \\ Brazil \\ ${ }^{5}$ Postgraduate Program in Integral Attention to Health, Regional University of Northwestern State's Rio Grande \\ do Sul (UNIJUI), Ijuí, Brazil \\ ${ }^{6}$ Department of Pharmacologic Sciences, Universidade Federal de Ciências da Saúde de Porto Alegre, Porto \\ Alegre, Brazil \\ Email: gpotrick@gmail.com
}

Received 30 May 2015; accepted 22 July 2015; published 27 July 2015

Copyright (C) 2015 by authors and Scientific Research Publishing Inc.

This work is licensed under the Creative Commons Attribution International License (CC BY).

http://creativecommons.org/licenses/by/4.0/

(c) (i) Open Access

\section{Abstract}

The Metabolic Syndrome (MetS) is a complex condition which is characterized by increased risk factor for cardiovascular diseases, such as dyslipidemia, hypertension and central obesity, in addition to increased risk for type 2 diabetes mellitus (T2DM). All of these factors alone have a notable relationship with DNA damage. However, when the risks are combined, the extent for major outcomes being related to DNA damage (cancer), the consequence can be accelerated by the metabolic dysfunction. This article will illustrate the scientific evidence of the role of DNA damage in MetS, as well as discuss the interplay of major risks factors (air pollution, physical inactivity and dietary interventions) in genomic stability.

${ }^{*}$ Corresponding author.

How to cite this paper: Stefani, G.P., Baldissera, G., Nunes, R.B., Heck, T.G. and Rhoden, C.R. (2015) Metabolic Syndrome and DNA Damage: The Interplay of Environmental and Lifestyle Factors in the Development of Metabolic Dysfunction. Open Journal of Endocrine and Metabolic Diseases, 5, 65-76. http://dx.doi.org/10.4236/ojemd.2015.57009 


\section{Keywords}

\section{Metabolic Syndrome, DNA Damage, Diet, Physical Activity, Air Pollution}

\section{Introduction}

The Metabolic Syndrome (MetS) is a set of multifactorial of metabolic and physiological abnormalities. This syndrome can be characterized by at least three of the major components of its pathophysiology, such as central obesity (waist circumference $>102 \mathrm{~cm}$ for men and $>88 \mathrm{~cm}$ for women), hypertension $(>139 \mathrm{mmHg}$ for systolic blood pressure and $>89 \mathrm{mHg}$ for diastolic blood pressure), dyslipidemia ( $>200 \mathrm{mg} / \mathrm{dL}$ of total cholesterol and/or $>200 \mathrm{mg} / \mathrm{dL}$ of triglycerides in fasting state) and hyperglycemia ( $>100 \mathrm{mg} / \mathrm{dL}$ in fasting state) [1]. These components lead to higher susceptibility for the progression of cardiovascular diseases. Furthermore, most of the components of the MetS have individually been linked somehow with the development of cancer [2].

The high prevalence of the MetS worldwide is well documented. This growth of MetS appears to be increasing due to a parallel growth in the prevalence of obesity. Its likelihood to maintain increasing may be a concern, since projections show significant rises of obesity in the future [3]. Epidemiological data show that in most countries, about $20 \%$ to $30 \%$ of the adult population can be characterized as carrier of MetS. The prediction to diabetes incidence is that it will double until 2025, representing an increase of parallel complications, which directly impacts on global healthcare systems [3] [4].

Of the main global leaders in mortality risks in the world, high blood pressure represents $13 \%$ of deaths worldwide, being even more impactful than tobacco use (9\%), hyperglycemia (6\%), physical inactivity (6\%) and overweight and obesity (5\%). These factors are responsible for increasing the risk of chronic diseases such as cardiovascular events, diabetes, cancer and MetS. Additionally, urban air pollution and indoor pollution are environmental factors that increase the risk for development and aggravation of MetS, increasing the mortality rates for any causes worldwide, contributing with $6.7 \%$ of all deaths [5]-[7]. The interaction of these factors promotes several licentious subclinical process in many organs, as inflammation and oxidative stress that explain the heath to disease process [8].

Oxidative stress may play a pivotal role in the development of MetS [9] [10]. The imbalance in the redox state, which can be represented by an increase between reactive oxygen species/reactive nitrogen species (ROS/RNS) and antioxidants defenses, may exceed total antioxidant capacity, leading to oxidative stress. This phenomenon can be observed in various pathophysiological conditions, including atherosclerosis, diabetes, obesity, and cancer and also induced by air pollution exposure. These conditions of oxidative stress may be characterized by reducing antioxidant defenses and by altering metabolic dysregulation, cell signaling, and other cellular functions [11]. In both diseases, each risk factor alone is related to oxidative DNA damage, but combined, several factors can accelerate the metabolic dysfunction accompanied by increased free radical attack to DNA.

The objective of this review was to address the relationship of DNA damage between MetS and its impact on associated factors that augments its severity. The review based on current published literature and our own experience is given. Articles written in English are searched in the National Library of Medicine's PubMed MedLine database and in the Web of Knowledge for metabolic syndrome, DNA damage, genotoxicity and oxidative stress.

\section{Pathophysiology of Metabolic Syndrome}

The pathophysiological mechanisms involved in MetS are represented by perceptible biomarker of metabolic disease, (elevated body mass index, central adiposity) [12], classical clinical parameters (obesity-related like hyperglycemia, hypertension as dyslipidemia) and several subclinical process and its consequences (increased circulating levels of pro-inflammatory cytokines and adipokines, lipid peroxides and oxidized DNA bases). Once the development of MetS it is complex and affects several biochemical and physiological systems in the body [13] [14], interventions requires different approaches as from medication to change lifestyle to counteract the MetS risk, and the comprehension of the pathological processes are fundamental to program new strategies for health improvements.

Central adiposity is associated to pathophysiological mechanisms in MetS. Adipose tissue secretes proteins 
and non-protein factors into the circulation, the adipokines, which modulates glucose and lipid metabolism. Leptin and adiponectin are both adipokines exclusively synthesized by adipocytes [13] [14]. Leptin is a key regulator of satiety and appetite and has a role on peripheral and cardiovascular metabolic mechanisms of enhancing pro-thrombotic platelet aggregation and endothelial dysfunction, stimulating the production of inflammatory cytokines and enhancing calcification of vascular cells [15] [16]. However, obese patients develop resistance to leptin, which is directly related to adiposity [2]. Adiponectin has been known as modulator of glucose and lipid metabolism in muscle and in the liver. Its mechanism for increasing insulin sensitivity is the activation of AMPK in the muscle or in the liver [17]. Despite of most obese patients presenting low levels of adiponectin, only the adipose tissue mass is responsible for negative correlation between adiponectin levels and insulin sensitivity [13]. In addition, there is a tissue-specific production of free radicals due to the synthesis of proinflammatory adipokines, which are promoted by an increased visceral fat [18].

Skeletal muscle represents a key point for maintenance of glucose homeostasis and is a target organ of the obesity process. Muscle metabolic function can be impaired by increasing the accumulation of visceral fat. The visceral adipocytes release non-esterified fatty acids, as well as the pro-inflammatory cytokine TNF- $\alpha$, and ROS. When non-esterified fatty acids accumulate in cells they undergo $\beta$-oxidation, forming acetyl-CoA that enters the Krebs cycle, representing a free radical industry. The excessive amount of ROS formed in this situation requires a protective response against oxidative stress: decrease the influx of glucose into the cell to avoid more free radical formation by glucose metabolism. Thus, the phosphorylation of tyrosine in IRS-1 as a "protective mechanism" that down-regulates insulin sensitivity in muscle, promotes insulin resistance, and then hyperglycemia [19]. Continuous insulin resistance increases and/or decreases in insulin secretory compensation responses, the deterioration of impaired glucose tolerance may occur. Increased glucose, free fat acid an insulin levels lead to ROS overproduction, increased oxidative stress and activate stress transduction factor pathways. This can cause insulin activity inhibition and secretion to accelerate the onset of T2DM [20].

In hyperglycemia state, glucose can be incorporated into proteins. Chronic hyperglycemia can lead to tissue damage and its mechanisms include glycation of proteins and excess production of polyol compounds from glucose [21]. Chronic hyperglycemia induced by insulin resistance, is characterized by high plasma insulin concentrations as consequence of impaired hormonal insulin signaling. Also, genetic abnormalities of proteins involved in insulin action cascade, malnutrition and high visceral adiposity are mechanisms that have been proposed to causing insulin resistance [22].

These metabolic changes can induce genotoxic stresses, stimulating two major insulin signaling pathways: phosphoinositide-3 kinase (PI3K) and mitogen-activated protein kinase (MAPK) pathways. PI3Ks are a family of intracellular signal transducer enzymes involved in cellular growth, proliferation, differentiation, motility, survival and intracellular trafficking. MAPKs are identified as stress-activated kinases involved in directing cellular responses to mitogens, osmotic and oxidative stress, heat shock proteins and proinflammatory cytokines, regulating proliferation, gene expression, differentiation, mitosis, cell survival, and apoptosis. Both signalling pathways activate extracellular signal-regulated kinases that mediate the mitogenic growth and pro-inflammatory responses of insulin [23] [24]. Moreover, in response of cellular stresses and DNA damage, tumor suppression protein p53 is activated, which directs cells to cell cycle arrest, senescence, or apoptosis regulating the transcription and activation of target genes [23] [25].

Hypertension is one of the criteria for MetS diagnosis and its pathophysiology has insulin resistance and central obesity as the main factors involved. The oxidative stress related to hypertension may affect endothelial cell functions, contributing to cardiovascular complications [26]. MetS is associated mainly with the salt-sensitive hypertension and the ROS play important role as a mechanical link in this condition [27]. Excessive abdominal fat (as observed in MetS) is related with ROS overproduction due to increase adipocytokines secretion such as TNF- $\alpha$, angiotensinogen, non-esterified fatty acids which leads to a disturbed sodium balance [28]. Also, the increase of central adiposity, thus, related to MetS, can increase the resistance of vessels, including renal arteries, establishing a major risk for increasing blood pressure by mechanical factors, as well as a disruption in the renin-angiotensin system.

Redón and colleagues (2003) found higher levels of damaged puric base, 8-oxo-2'-deoxyguanosine, in nuclear and mitochondrial deoxyribonucleoproteins on hypertensive subjects than normotensive control subjects. The cytokines, ROS and lipids released from adipose tissue to bloodstream may contribute to endothelium dysfunction and impaired autonomic pressure regulation. The inflammation process in endothelium is related to 
oxidative stress, which promotes oxidation of LDL, macrophage infiltration and foam cell formation induced by cytokine signaling to chemotaxis and intracellular inflammatory process [30].

\section{DNA Damage and Its Associations with Oxidative Stress in Metabolic Syndrome}

ROS production is a natural phenomenon inside aerobic metabolism organism. The increase in the energy demand usually result in high influx of $\mathrm{O}_{2}$ in the mitochondrial reactions that results in ROS overproduction. Free radicals have many physiological functions, however have high reactivity to adjacent biomolecules. It is well established that the overproduction of reactive species leads to the impairment of important cellular structures such as lipid peroxidation (mainly in plasmatic membranes), damage in proteins (signaling proteins, enzymes and other proteins) and genomic damage (oxidation of nucleic acids). Tornovsky-Babeay and colleagues (2014) suggests that excessive glucose metabolism in cells can leads to double-strand breaks (DSB) in the DNA, activation of p53, and apoptosis via oxidative stress. In MetS, the balance of ROS and RNS generation, as well as antioxidant system seems to be affected by several factors, leading to higher susceptibility to cardiovascular events [32].

There are evidences that this type of injury markers are elevated in diabetic patients. The complications of hyperglycemia are related with higher production of ROS and RNS, which promotes lipids oxidation and micro and macro vascular complications. When extracellular glucose concentrations are elevated, these complications occur due to the failure of cells to down-regulate their glucose uptake [22] [33]. Current evidences suggests that glucose-induced oxidative stress is a mechanism for glucose toxicity. Hyperglycemia generates ROS in $\beta$-cells, due to glucose overload in these cells [34]. Oxidative stress can induce apoptosis through p53-dependent mechanism. $\beta$-cells expresses the trans-gene p53, so, deficiency in p53 can prevent cell death by glucotoxicity, but it does not interfere directly with metabolic processes that cause cell dysfunction, such as ROS production [31].

Hyperglycemia per se is also known to be involved in inflammation and diabetes-associated vascular complications induced by ROS. The free radical gas nitric oxide $\left(\mathrm{NO}^{*}\right)$ is synthesized at high rates by the inducible form of nitric oxide synthase (iNOS). Although NO is required to stimulate essential functions such as muscle GLUT4 expression/translocation and insulin secretion by $\beta$-cells, at high concentrations, NO compromises insulin-stimulated glucose transport in skeletal muscle and can also be toxic to $\beta$-cells inducing DNA damage. $\mathrm{NO}^{*}$ overload results in a reduction of insulin stimulated-glucose uptake and glycogen synthesis in muscle, lowering the activity of IR $\beta$ and IRS-1. This mechanism is accompanied by the impairment in intracellular stress response (heat shock protein $70 \mathrm{kDa}$ expression) in muscle [35] and liver [36]. Also, altered metabolic state can serve as stimulus to heat shock protein release (extracellular heat shock proteins), which is accompanied by cytokine release [37]. These circulating elements (heat shock proteins and cytokines) are related to pro-inflammatory signaling from immune system to whole body [38] that represents low-grade inflammation of MetS [39]. Although TNF- $\alpha$ is strongly related to obesity, the polymorphism of TNF- $\alpha$ is not related to obesity while genetic variation in the stress protein is highly associated with obesity [40].

\section{Repair Mechanisms of DNA Damage}

Oxidative DNA lesions comprises DNA strand breaks and base modifications. which may be repaired by the DNA base excision repair (BER) [41]-[43]. If the DNA strand is broken, it can be reconnected to another position, thereby changing the order of its bases. This is one of the basic processes of mutation and the accumulation of oxidatively damaged bases can trigger oncogenesis.

The cell has different enzymes that can exert important role in DNA damage. The 8-oxoguanine DNA glycosylase (OGG1) is a major repair enzyme of oxidation products of guanine, such as 7, 8-dihydro-8-oxoguanine (8-oxoG), which is the most predominant mutagenic ROS-induced DNA lesion [42] [44]. In the presence of 8-oxoG base, OGG1 acts as a guanine nucleotide exchange factor, catalyzing the release of oxidized purines from DNA, by excision of the damaged nucleotide and its replacement with a new undamaged one via BER.

If DNA alterations remains unrepaired, these changes may interfere with DNA replication and transcription, resulting in the accumulation of mutations [45]. Pathological processes, such as cancer, has been linked to the unrepaired lesion in the genome caused by 8-oxoG. Sequence analysis of p53 tumor suppressor gene, commonly mutated in several types of cancer, indicates a high number of conversions cytosine-guanine: thymine-adenine (CG: TA), probably resulting from a deficiency in OGG1.

Recently, another protein has gained attention, the p53-binding protein 1 (53BP1), which exerts important 
role in regulate the cellular response to double strand breaks of DNA [46]. The DSB are major issue in genomic stability, since the consequences of excessive DSB are strongly related to the development of cancer [47]. The 53BP1 binds to the damaged chromatin and demonstrates to be an antagonist in DSB repair pathway. For instance, when binding to damaged chromatin along with the methylated form, the 53BP1 induces to non-homologous end-joining mediated repair. In another approach, the inhibition of 53BP1 might occurs in the S and G2 phase of cell cycle, in which the non binding action of 53BP1 with the acetylated histone, the DNA repair of DSB can be shifted towards homologous recombination [46].

\section{Associated Factors to DNA Damage in Metabolic Syndrome}

The outcomes from a pathophysiological event, generally affects the antioxidant system. As it was discussed above, not only damage to biomolecules can determinate the severity of the disease, but the genotoxicity may indicate the amplitude of oxidative damage. MetS can have different primary components, such as obesity, hypertension, diabetes and so on. Accordingly to the literature, it seems that this set of metabolic disorders can influence the extent of DNA damage. In Figure 1, it is represented the harmful and protection factors that may affect MetS.

Since ROS/RNS are the major source of endogenous genotoxic damage, MetS patients shows remarkably higher nuclear DNA damage in peripheral blood, compared to healthy subjects [48]. Also, in the study, Karaman and colleagues were able to show that subjects with MetS also demonstrated higher glycated hemoglobin (HbA1c), systolic and diastolic blood pressure, as well as higher visceral fat in waist circumference and were associated with DNA damage.

The DNA damage can demonstrate a wide variety of results, however, the permanent damage must be quantified by other means. For that, the micronuclei assay which determinates the frequency of binucleated cells is a trustworthy and sensitive technique to quantify mutagenesis [49]. It has been demonstrated that the frequency of mutagenesis of patients with MetS are approximately $100 \%$ higher than healthy subjects and was positively correlated with waist circumference, BMI and with plasma triglycerides [48]. Once the mutagenic process is established, the risk of developing to cancers is remarkably higher. Not all types of cancers have been related to MetS, but breast, liver, gallbladder and pancreatic cancer demonstrate epidemiological evidences that the increase of central adiposity is a major risk factor [50].

Also, high-fat diets may impair insulin sensitivity and can induce mitochondrial DNA damage in mice which was associated with mitochondrial dysfunction and oxidative stress in skeletal muscle and in liver [51].

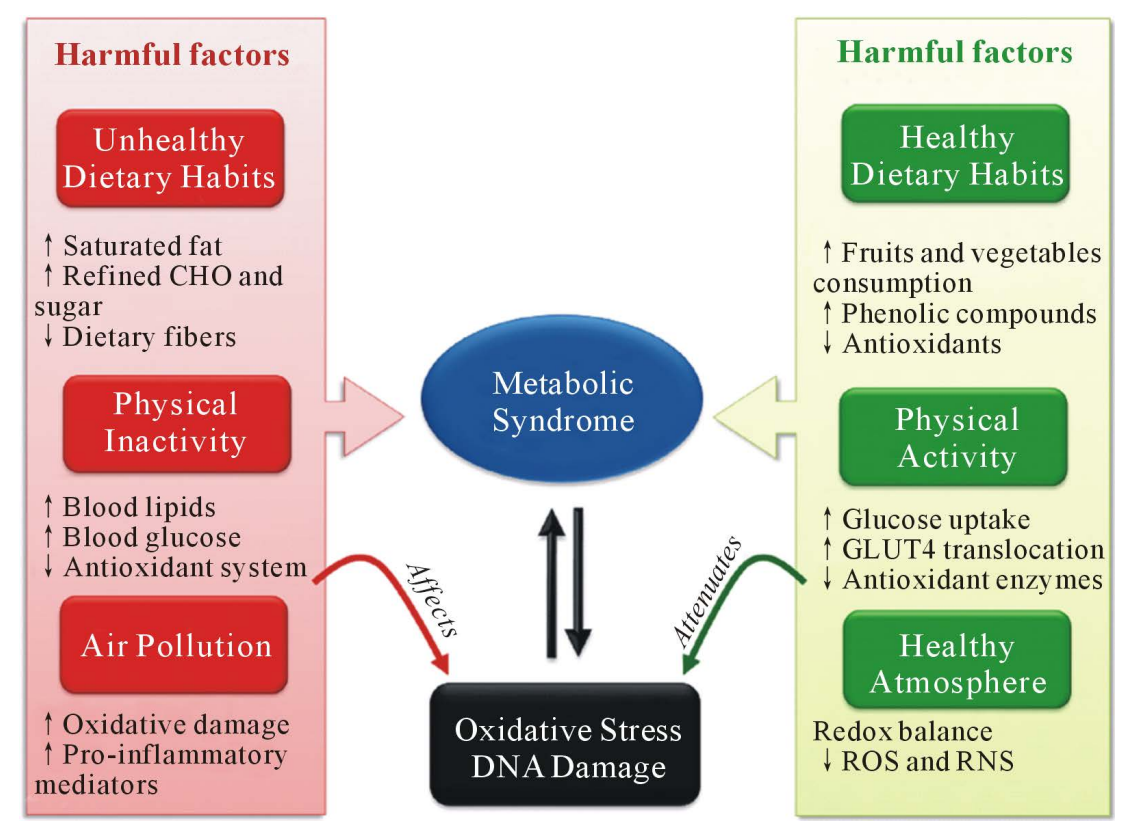

Figure 1. The interplay of harmful and protection factors of DNA damage in Metabolic Syndrome. 


\subsection{Environmental Factors}

The inter-relationship between atmospheric pollution and oxidative stress has been extensively studied [52]. Innumerous reports regarding antioxidant status in different populations with or without any disorder indicated that particulate matter as the major cause of redox imbalance. Particulate matter has different sizes and its oxidative effects are notably size-dependent [53] [54].

The inhalation of airborne particulate matter can cause a series of oxidative damage in humans. The main issue of the fine and ultrafine particulate matter is its size $(<2.5 \mu \mathrm{m})$ and by this small size, can reach bloodstream and alveolar structures [55]. These particles can affect hemodynamic responses by the increase in sympathetic tone, as well as superoxide inhibition of the action of NO in endothelial relaxation [56]. Also, its composition are constituted by a significant portion of heavy metals, such as iron and aluminum. As a result of containing metals, the particulate matter can directly induce the formation of free radicals, thus increasing the risk of damaging the DNA [57].

It has been widely demonstrated that urban areas area more polluted than rural areas [58] [59]. Since a significant part of obese individuals live in a polluted environment, for instance in major cities, the disease itself exerts chronic pro-oxidant and proinflammatory effect. In a recent investigation, Devlin and colleagues (2014) sought to submit individuals with MetS to a controlled exposure to concentrated ultrafine ambient particulate matter. The The researchers evaluated the presence of a polymorphism in enzymatic antioxidant system. The study aimed to evaluate the effects of glutathione-S-transferase M1 (GSTM1) polymorphism in polluted areas, which is present in approximately $40 \%$ of the population [60]. The result of the acute exposure, demonstrated that individuals with MetS that possessed GSTM1 polymorphism were more susceptible to cardiovascular alterations, such as heart rate variability, which could increase the risk of cardiovascular events [61].

As an attempt to demonstrate the interaction of the oxidative burden of individuals with MetS, Abdilla and colleagues (2007) evaluated oxidative DNA damage in this population with and without hypertension. It was observed that the presence of hypertension in individuals with MetS has a minimal oxidative burden, compared to hyperglycemia. It is noteworthy to emphasize that the sample used in this study does not represent the population with MetS, once the mean BMI (Body Mass Index) found was $29.2 \mathrm{~kg} / \mathrm{m}^{2}$. Individuals with MetS often show BMI higher than $30.0 \mathrm{~kg} / \mathrm{m}^{2}$, demonstrating a possible explanation to lower oxidative burden in hypertensive patients with MetS.

\subsection{Physical Inactivity}

Physical inactivity can be defined as not meeting any of the following criteria: a) 30 minutes of moderate-intensity physical activity on at least 5 days each week; b) 20 minutes of vigorous-intensity physical activity on at least 3 days each week; c) an equivalent combination achieving 600 metabolic equivalent task (MET) min per week [63].

It is well established that physical inactivity can lead to a series of non-communicable diseases, such as obesity, T2DM, hypertension and MetS [64]-[66]. Recently, it has been estimated that approximately 35\% of the population worldwide does not meet the present recommendations for physical activity [67]. The outcomes of being physically inactive comprises 5.8\% higher chances to develop coronary heart disease and $7.2 \%$ higher chances to develop type 2 diabetes [67]. The systemic oxidative stress including higher levels of lipid peroxidation and lower antioxidant defense capacity is related to a lower aerobic capacity and impaired skeletal muscle energy metabolism in patients with MetS [68]. On the other hand, recent evidences shows that regular exercises can directly modulate antioxidant defense system with significant increases in catalase, superoxide dismutase, glutathione peroxidase expression and activity, as well as it can decrease insulin resistance and inflammatory markers in obese men [69].

Physical inactivity has a major health impact on the world. Elimination of physical inactivity would remove between $6 \%$ to $10 \%$ of major non-communicable diseases, such as chronic heart failure, T2DM, breast and colon cancer, as well it would increase life expectancy [67]. The benefits of regular exercise training with insulin sensibility, inflammatory profile and antioxidant states can be observed even without significant global weight loss [70].

Since physical training increases functional health, cardiorespiratory and muscular fitness, it does not certificate that other environmental factors might influence its effect. For instance, in urban areas air pollution is a major problem for respiratory diseases. Exercising in polluted areas might lead to oxidative damage. Experi- 
mental models of particulate matter inhalation and urban ambient particles associated with exercise demonstrated to aggravate oxidative stress [71]-[73]. However, few studies sought to evaluate genotoxic responses to acute and chronic exercises in MetS condition.

Regarding the acute responses of exercise, one isolated session of exercise is related with improvement in insulin sensitivity because of weight loss, reduction of body fat, and optimizing glucose uptake after physical activity, due to increase in GLUT4 (Glucose Transporter type 4) [22]. In one of the few investigations regarding the chronic effect of exercise without MetS, Radak and colleagues (2009) reported that swimming (duration of 8 weeks) was able to improve the level/activity of DNA damage repair of the enzyme 8-oxoguanine-DNA glycosylase [74]. The researchers also observed that physical training positively affected oxidized nuclear and mitochondrial DNA bases, indicating a genotoxic protection induced by the exercise and possibly may be an important intervention in patients with MetSs.

\subsection{Dietary Interventions}

Nutritional aspects are involved in prevention as well as in treatment in MetS complications, such as glycemic control and weight loss by modifications on eating behavior. However, its quality of micronutrients can actually show notable oxidative DNA damage protection [75]. It has been firstly demonstrated that the dietary cholesterol can influence in serum cholesterol levels [76]. The consumption of nuts has gained attention once it was demonstrated an inverse association of nut consumption with total and cause-specific mortality in healthy adults (mean age of 60 years) [77]. Also regarding nuts consumption, it has been recently demonstrated that the consumption of 60 grams per day of soy nuts in patients with T2DM for eight weeks was able to reduce fasting blood glucose, insulin concentration, as well as systolic and diastolic blood pressure [78].

The effect of hypocaloric diet was studied by Reis and colleagues (2014) in women with MetS for 16 weeks. It was observed significant reductions in total body mass, BMI, waist circumference, systolic and diastolic arterial blood pressure, as well as increase in plasma levels of HDL cholesterol, reduction in plasma level of total cholesterol, triglycerides, and LDL cholesterol. The intervention was based on a decrease in the consumption of energy and dietary lipids, and an increase in the consumption of monounsaturated fatty acids.

In a well designed experiment, van Dijk and colleagues (2009) tested the difference of saturated fatty acidrich diet (SFA) to monounsaturated fatty acid-rich diet (MUFA) on gene expression of inflammatory profile in subjects with risk to develop MetS. In a 8 week protocol, the subjects that consumed SFA-rich diet showed notable increase of gene expression implicated in inflammation pathway in adipose tissue, such as peroxisome proliferator-activated receptor- $\gamma$, integrin $\beta 2$ and cathepsin S. The increase of proinflammatory gene expression occurred regardless of changes in morphology or insulin sensitivity. The modification of the proportion of MUFA in diets for this population may prevent adipose tissue inflammation, thus, diminishing the risk to develop inflammation-related disorders.

Recently it has been demonstrated that nutrients might exert synergistic effects in MetS coadjuvant treatment. In approximately 100 patients (majority men, 80\%) the association of $3 \mathrm{~g} /$ day of fish oil with $10 \mathrm{~mL} /$ day of extra virgin olive oil, oxidative stress parameters, such as total peroxyl radical-trapping (TRAP), were measured at the beginning of the intervention and measured again after 90 days to compare with control group and also with fish oil supplementation alone, as well as extra virgin olive oil alone. In this study, the group that received both oils showed a remarkable decrease in total cholesterol, low-density lipoprotein cholesterol and in hydroperoxides. This intervention showed evidence for future investigations to test the strength of the association of fish oil with extra virgin olive oil in patients with MetS [81].

Although caloric restriction results on weight loss and its consequences ameliorates MetS complications, is important pay attention to quality of nutritional interventions. There are evidences that low carbohydrate diets would provide benefits to MetS symptoms in function of maintain low levels of insulin. However, is well know that dyslipidemia and central obesity are involved on insulin resistance state. Since hyperglycemia it is considered one of the major factors impacting in oxidative stress, on the other hand, the increase in protein would be deleterious for type 2 diabetics because of the increase in glucose due to gluconeogenesis [82].

Esmaillzadeh and colleagues (2007) found that the dietary pattern characterized by consumption of high fiber foods, such as fruits, vegetables and legumes was associated with reduced risk of insulin resistance and the MetS. Moreover, the high consumption of refined grains, red meat, processed meat, butter, and high-fat dairy associated with low consumptions of vegetables and low-fat dairy were directly related to greater risk of developing MetS in women. 
The Mediterranean diet is known by the high consumption of fruits, vegetables, fish, nuts and extra virgin olive oil, which is rich in vitamins, minerals and antioxidant phenolic content. Mitjavila and colleagues (2013) investigated the effect of this diet on systemic oxidative biomarkers in MetS individuals. In a randomized controlled trial which is part of a large multicenter study, the PREDIMED [85], 110 women with MetS were enrolled to a 1-year intervention of Mediterranean diet alone or associated with extra virgin olive oil to assess the oxidative stress parameters, as well as DNA damage. In this trial, dietitians have visited the subjects at baseline and every 3 months to provide dietetic support for the Mediterranean diet. The group that consumed extra virgin olive oil had to consume approximately $1 \mathrm{~L} /$ week for one year. The results from this trial were remarkably promising, the group of Mediterranean diet associated to olive oil demonstrated lower oxidative damage to lipids and DNA. The oxidative damage that was evaluated in urine (8-oxo-dG), characterized as a reliable marker to assess oxidative DNA damage.

In a different approach, a dietary intervention containing green algae mixture of Scenedesmus dimorphus and Schroederiella apiculata attenuated MetS physiological alterations in rats. The diet promoted significant reduction in impaired glucose tolerance, as well as insulin sensitivity, fat deposition (mainly visceral fat), hypertension and collagen deposition in heart in rats submitted to a high fat diet [86]. The effects observed of attenuating MetS symptoms induced by the diet by the green algae mixture seems to be related to the insoluble fiber, as well as the protein present in this association.

The choice of interventions is based on individual genetic and lifestyle conditions and assessments of risk factors involved. However, reducing the intake in dietary saturated fat and an increasing in high-fiber foods (fruits, vegetables, legumes) are recommendations that may be successful in preventing weight gain [87], as well as in weight loss and in its consequences control of complications of MetS.

\section{Conclusion}

The MetS affects a wide variety of systems and organs. The DNA damage can play an important role in its severity. Few environmental factors can modify the fierceness of pathological alterations in patients with MetS, such as air pollution, physical inactivity and diet. Despite the severity that this factor might affect, all of them are remarkably modifiable. Changing lifestyle habits might promote beneficial effects not only in cardiovascular health, but also in the risk for developing cancer, which is related to DNA damage. In a near future, once the scientific investigations are performed regarding the mechanisms and impact that DNA damage can elicit in MetS, new strategies for preventing major complications, such as obesity-related tumorigenesis, become the main challenge for scientists and healthcare professionals.

\section{Competing Interests}

The authors declare that they have no competing interests.

\section{References}

[1] Cameron, A.J., Shaw, J.E. and Zimmet, P.Z. (2004) The Metabolic Syndrome: Prevalence in Worldwide Populations. Endocrinology and Metabolism Clinics of North America, 33, 351-375. http://dx.doi.org/10.1016/j.ecl.2004.03.005

[2] Cowey, S. and Hardy, R.W. (2006) The Metabolic Syndrome: A High-Risk State for Cancer? The American Journal of Pathology, 169, 1505-1522. http://dx.doi.org/10.2353/ajpath.2006.051090

[3] Grundy, S.M. (2008) Metabolic Syndrome Pandemic. Arterioscler Thromb Vasc Biol., 28, 629-636. http://dx.doi.org/10.1161/ATVBAHA.107.151092

[4] Alberti, K.G., Zimmet, P. and Shaw, J. (2005) The Metabolic Syndrome-A New Worldwide Definition. The Lancet, 366, 1059-1062. http://dx.doi.org/10.1016/S0140-6736(05)67402-8

[5] Fajersztajn, L., Veras, M., Barrozo, L.V. and Saldiva, P. (2013) Air Pollution: A Potentially Modifiable Risk Factor for Lung Cancer. Nature Reviews Cancer, 13, 674-678. http://dx.doi.org/10.1038/nrc3572

[6] Lepeule, J., Laden, F., Dockery, D. and Schwartz, J. (2012) Chronic Exposure to Fine Particles and Mortality: An Extended Follow-Up of the Harvard Six Cities Study from 1974 to 2009. Environmental Health Perspectives, 120, 965970. http://dx.doi.org/10.1289/ehp.1104660

[7] Pope 3rd, C.A., et al. (2002) Lung Cancer, Cardiopulmonary Mortality, and Long-Term Exposure to Fine Particulate Air Pollution. JAMA, 287, 1132-1141. http://dx.doi.org/10.1001/jama.287.9.1132 
[8] Eze, I.C., et al. (2014) Long-Term Air Pollution Exposure and Diabetes in a Population-Based Swiss Cohort. Environment International, 70, 95-105. http://dx.doi.org/10.1016/j.envint.2014.05.014

[9] Furukawa, S., et al. (2004) Increased Oxidative Stress in Obesity and Its Impact on Metabolic Syndrome. Journal of Clinical Investigation, 114, 1752-1761. http://dx.doi.org/10.1172/JCI21625

[10] Roberts, C.K. and Sindhu, K.K. (2009) Oxidative Stress and Metabolic Syndrome. Life Sciences, 84, 705-712. http://dx.doi.org/10.1016/j.lfs.2009.02.026

[11] Schafer, F.Q. and Buettner, G.R. (2001) Redox Environment of the Cell as Viewed through the Redox State of the Glutathione Disulfide/Glutathione Couple. Free Radical Biology and Medicine, 30, 1191-1212. http://dx.doi.org/10.1016/S0891-5849(01)00480-4

[12] Pinkhasov, B.B., Selyatitskaya, V.G., Karapetyan, A.R. and Astrakhantseva, E.L. (2012) Metabolic Syndrome in Men and Women with Upper or Lower Types of Body Fat Distribution. Health, 4, 1381-1389. http://dx.doi.org/10.4236/health.2012.412A200

[13] Nawrocki, A.R. and Scherer, P.E. (2004) The Delicate Balance between Fat and Muscle: Adipokines in Metabolic Disease and Musculoskeletal Inflammation. Current Opinion in Pharmacology, 4, 281-289. http://dx.doi.org/10.1016/j.coph.2004.03.003

[14] Srinivasan, V., Ohta, Y., Espino, J., Pariente, J.A., Rodriguez, A.B., Mohamed, M., et al. (2013) Metabolic Syndrome, Its Pathophysiology and the Role of Melatonin. Recent Patents on Endocrine, Metabolic \& Immune Drug Discovery, 7, 11-25. http://dx.doi.org/10.2174/187221413804660953

[15] Ren, J. (2004) Leptin and Hyperleptinemia—From Friend to Foe for Cardiovascular Function. Journal of Endocrinology, 181, 1-10. http://dx.doi.org/10.1677/joe.0.1810001

[16] Sweeney, G. (2010) Cardiovascular Effects of Leptin. Nature Reviews Cardiology, 7, 22-29. http://dx.doi.org/10.1038/nrcardio.2009.224

[17] Kadowaki, T., Yamauchi, T., Kubota, N., Hara, K., Ueki, K. and Tobe, K. (2006) Adiponectin and Adiponectin Receptors in Insulin Resistance, Diabetes, and the Metabolic Syndrome. Journal of Clinical Investigation, 116, $1784-1792$. http://dx.doi.org/10.1172/JCI29126

[18] Tesauro, M., Canale, M.P., Rodia, G., Di Daniele, N., Lauro, D., Scuteri, A., et al. (2011) Metabolic Syndrome, Chronic Kidney, and Cardiovascular Diseases: Role of Adipokines. Cardiology Research and Practice, 2011, Article ID: 653182. http://dx.doi.org/10.4061/2011/653182

[19] Heck, T.G., Ludwig, M.S., Montagner, G.F.F.S. and Frizzo, M.N. (2015) Subclinical Processes in the Development of Type Two Diabetes. Journal of Novel Physiotherapies, 5, 246.

[20] Tangvarasittichai, S. (2015) Oxidative Stress, Insulin Resistance, Dyslipidemia and Type 2 Diabetes Mellitus. World Journal of Diabetes, 6, 456-480. http://dx.doi.org/10.4239/wjd.v6.i3.456

[21] Nowotny, K., Jung, T., Hohn, A., Weber, D. and Grune, T. (2015) Advanced Glycation End Products and Oxidative Stress in Type 2 Diabetes Mellitus. Biomolecules, 5, 194-222. http://dx.doi.org/10.3390/biom5010194

[22] Venkatasamy, V.V., Pericherla, S., Manthuruthil, S., Mishra, S. and Hanno, R. (2013) Effect of Physical Activity on Insulin Resistance, Inflammation and Oxidative Stress in Diabetes Mellitus. Journal of Clinical and Diagnostic Research: JCDR, 7, 1764-1766.

[23] Erol, A. (2010) Systemic DNA Damage Response and Metabolic Syndrome as a Premalignant State. Current Molecular Medicine, 10, 321-334. http://dx.doi.org/10.2174/156652410791065282

[24] Nystrom, F.H. and Quon, M.J. (1999) Insulin Signalling: Metabolic Pathways and Mechanisms for Specificity. Cellular Signalling, 11, 563-574. http://dx.doi.org/10.1016/S0898-6568(99)00025-X

[25] Surova, O. and Zhivotovsky, B. (2013) Various Modes of Cell Death Induced by DNA Damage. Oncogene, 32, 37893797. http://dx.doi.org/10.1038/onc.2012.556

[26] Harrison, D.G. and Gongora, M.C. (2009) Oxidative Stress and Hypertension. Medical Clinics of North America, 93, 621-635. http://dx.doi.org/10.1016/j.mcna.2009.02.015

[27] Fujita, T. (2007) Insulin Resistance and Salt-Sensitive Hypertension in Metabolic Syndrome. Nephrology Dialysis Transplantation, 22, 3102-3107. http://dx.doi.org/10.1093/ndt/gfm409

[28] Fujita, T. (2008) Aldosterone in Salt-Sensitive Hypertension and Metabolic Syndrome. Journal of Molecular Medicine, 86, 729-734. http://dx.doi.org/10.1007/s00109-008-0343-1

[29] Redon, J., Oliva, M.R., Tormos, C., Giner, V., Chaves, J., Iradi, A., et al. (2003) Antioxidant Activities and Oxidative Stress Byproducts in Human Hypertension. Hypertension, 41, 1096-1101. http://dx.doi.org/10.1161/01.HYP.0000068370.21009.38

[30] Homem de Bittencourt Jr., P.I., Lagranha, D.J., Maslinkiewicz, A., Senna, S.M., Tavares, A.M.V., Baldissera, L.P., et al. (2007) LipoCardium: Endothelium-Directed Cyclopentenone Prostaglandin-Based Liposome Formulation That 
Completely Reverses Atherosclerotic Lesions. Atherosclerosis, 193, 245-258.

http://dx.doi.org/10.1016/j.atherosclerosis.2006.08.049

[31] Tornovsky-Babeay, S., Dadon, D., Ziv, O., Tzipilevich, E., Kadosh, T., Haroush, R.S.-B., et al. (2014) Type 2 Diabetes and Congenital Hyperinsulinism Cause DNA Double-Strand Breaks and p53 Activity in Beta Cells. Cell Metabolism, 19, 109-121. http://dx.doi.org/10.1016/j.cmet.2013.11.007

[32] Hutcheson, R. and Rocic, P. (2012) The Metabolic Syndrome, Oxidative Stress, Environment, and Cardiovascular Disease: The Great Exploration. Experimental Diabetes Research, 2012, Article ID: 271028. http://dx.doi.org/10.1155/2012/271028

[33] Giacco, F. and Brownlee, M. (2010) Oxidative Stress and Diabetic Complications. Circulation Research, 107, 10581070. http://dx.doi.org/10.1161/CIRCRESAHA.110.223545

[34] Robertson, R.P., Harmon, J., Tran, P.O. and Poitout, V. (2004) Beta-Cell Glucose Toxicity, Lipotoxicity, and Chronic Oxidative Stress in Type 2 Diabetes. Diabetes, 53, S119-S124. http://dx.doi.org/10.2337/diabetes.53.2007.S119

[35] Chung, J., Nguyen, A.-K., Henstridge, D.C., Holmes, A.G., Chan, M.H.S., Mesa, J.L., et al. (2008) HSP72 Protects against Obesity-Induced Insulin Resistance. Proceedings of the National Academy of Sciences of the United States of America, 105, 1739-1744. http://dx.doi.org/10.1073/pnas.0705799105

[36] Di Naso, F.C., Porto, R.R., Fillmann, H.S., Maggioni, L., Padoin, A.V., Ramos, R.J., et al. (2015) Obesity Depresses the Anti-Inflammatory HSP70 Pathway, Contributing to NAFLD Progression. Obesity, 23, 120-129. http://dx.doi.org/10.1002/oby.20919

[37] Ludwig, M.S., Minguetti-Câmara, V.C., Heck, T.G., Scomazzon, S.P., Nunes, P.R., Bazotte, R.B., et al. (2014) ShortTerm but Not Long-Term Hypoglycaemia Enhances Plasma Levels and Hepatic Expression of HSP72 in InsulinTreated Rats: An Effect Associated with Increased IL-6 Levels but Not with IL-10 or TNF-alpha. Molecular and Cellular Biochemistry, 397, 97-107. http://dx.doi.org/10.1007/s11010-014-2176-2

[38] Heck, T.G., Scholer, C.M. and de Bittencourt, P.I. (2011) HSP70 Expression: Does It a Novel Fatigue Signalling Factor from Immune System to the Brain? Cell Biochemistry and Function, 29, 215-226. http://dx.doi.org/10.1002/cbf.1739

[39] Rodrigues-Krause, J., Krause, M., O’Hagan, C., De Vito, G., Boreham, C., Murphy, C., et al. (2012) Divergence of Intracellular and Extracellular HSP72 in Type 2 Diabetes: DOES Fat Matter? Cell Stress and Chaperones, 17, 293-302. http://dx.doi.org/10.1007/s12192-011-0319-x

[40] Chouchane, L., Danguir, J., Beji, C., Bouassida, K., Camoin, L., Sfar, H., et al. (2001) Genetic Variation in the Stress Protein hsp70-2 Gene Is Highly Associated with Obesity. International Journal of Obesity, 25, 462-466. http://dx.doi.org/10.1038/sj.ijo.0801545

[41] Feng, B., Ruiz, M.A. and Chakrabarti, S. (2013) Oxidative-Stress-Induced Epigenetic Changes in Chronic Diabetic Complications. Canadian Journal of Physiology and Pharmacology, 91, 213-220. http://dx.doi.org/10.1139/cjpp-2012-0251

[42] Hazra, T.K., Das, A., Das, S., Choudhury, S., Kow, Y.W. and Roy, R. (2007) Oxidative DNA Damage Repair in Mammalian Cells: A New Perspective. DNA Repair, 6, 470-480. http://dx.doi.org/10.1016/j.dnarep.2006.10.011

[43] El-Wassef, M., El-Saeed, G.S.M., El-Tokhy, S.E., Raslan, H.M., Tawfeek, S., Siam, I., et al. (2012) Oxidative DNA Damage in Patients with Type 2 Diabetes Mellitus. Diabetologia Croatica, 41, 121-127.

[44] Boldogh, I., Hajas, G., Aguilera-Aguirre, L., Hegde, M.L., Radak, Z., Bacsi, A., et al. (2012) Activation of Ras Signaling Pathway by 8-Oxoguanine DNA Glycosylase Bound to Its Excision Product, 8-Oxoguanine. The Journal of Biological Chemistry, 287, 20769-20773. http://dx.doi.org/10.1074/jbc.C112.364620

[45] Dianov, G.L. and Hubscher, U. (2013) Mammalian Base Excision Repair: The Forgotten Archangel. Nucleic Acids Research, 41, 3483-3490. http://dx.doi.org/10.1093/nar/gkt076

[46] Panier, S. and Boulton, S.J. (2014) Double-Strand Break Repair: 53BP1 Comes into Focus. Nature Reviews Molecular Cell Biology, 15, 7-18. http://dx.doi.org/10.1038/nrm3719

[47] Srivastava, M. and Raghavan, S.C. (2015) DNA Double-Strand Break Repair Inhibitors as Cancer Therapeutics. Chemistry \& Biology, 22, 17-29. http://dx.doi.org/10.1016/j.chembiol.2014.11.013

[48] Karaman, A., Aydin, H., Geckinli, B., Cetinkaya, A. and Karaman, S. (2015) DNA Damage Is Increased in Lymphocytes of Patients with Metabolic Syndrome. Mutation Research/Genetic Toxicology and Environmental Mutagenesis, 782, 30-35. http://dx.doi.org/10.1016/j.mrgentox.2015.03.009

[49] Fenech, M. (2007) Cytokinesis-Block Micronucleus Cytome Assay. Nature Protocols, 2, 1084-1104. http://dx.doi.org/10.1038/nprot.2007.77

[50] Calle, E.E. and Kaaks, R. (2004) Overweight, Obesity and Cancer: Epidemiological Evidence and Proposed Mechanisms. Nature Reviews Cancer, 4, 579-591. http://dx.doi.org/10.1038/nrc1408 
[51] Yuzefovych, L.V., Musiyenko, S.I., Wilson, G.L. and Rachek, L.I. (2013) Mitochondrial DNA Damage and Dysfunction, and Oxidative Stress Are Associated with Endoplasmic Reticulum Stress, Protein Degradation and Apoptosis in High Fat Diet-Induced Insulin Resistance Mice. PLoS ONE, 8, e54059. http://dx.doi.org/10.1371/journal.pone.0054059

[52] Gong, J., Zhu, T., Kipen, H., Wang, G., Hu, M., Guo, Q., et al. (2014) Comparisons of Ultrafine and Fine Particles in Their Associations with Biomarkers Reflecting Physiological Pathways. Environmental Science \& Technology, 48, 5264-5273. http://dx.doi.org/10.1021/es5006016

[53] Brook, R.D., Rajagopalan, S., Arden Pope III, C., Brook, J.R., Bhatnagar, A., Diez-Roux, A.V., et al. (2010) Particulate Matter Air Pollution and Cardiovascular Disease: An Update to the Scientific Statement from the American Heart Association. Circulation, 121, 2331-2378. http://dx.doi.org/10.1161/CIR.0b013e3181dbece1

[54] Martinelli, N., Olivieri, O. and Girelli, D. (2013) Air Particulate Matter and Cardiovascular Disease: A Narrative Review. European Journal of Internal Medicine, 24, 295-302. http://dx.doi.org/10.1016/j.ejim.2013.04.001

[55] Sawyer, K., Mundandhara, S., Ghio, A.J. and Madden, M.C. (2010) The Effects of Ambient Particulate Matter on Human Alveolar Macrophage Oxidative and Inflammatory Responses. Journal of Toxicology and Environmental Health, Part A, 73, 41-57. http://dx.doi.org/10.1080/15287390903248901

[56] Kannan, S., Misra, D.P., Dvonch, J.T. and Krishnakumar, A. (2006) Exposures to Airborne Particulate Matter and Adverse Perinatal Outcomes: A Biologically Plausible Mechanistic Framework for Exploring Potential Effect Modification by Nutrition. Environmental Health Perspectives, 114, 1636-1642.

[57] Risom, L., Møller, P. and Loft, S. (2005) Oxidative Stress-Induced DNA Damage by Particulate Air Pollution. Mutation Research/Fundamental and Molecular Mechanisms of Mutagenesis, 592, 119-137. http://dx.doi.org/10.1016/j.mrfmmm.2005.06.012

[58] Apeagyei, E., Bank, M.S. and Spengler, J.D. (2011) Distribution of Heavy Metals in Road Dust Along an Urban-Rural Gradient in Massachusetts. Atmospheric Environment, 45, 2310-2323. http://dx.doi.org/10.1016/j.atmosenv.2010.11.015

[59] Lawson, S.J., Galbally, I.E., Powell, J.C., Keywood, M.D., Molloy, S.B., Cheng, M., et al. (2011) The Effect of Proximity to Major Roads on Indoor Air Quality in Typical Australian Dwellings. Atmospheric Environment, 45, $2252-$ 2259. http://dx.doi.org/10.1016/j.atmosenv.2011.01.024

[60] Garte, S., Gaspari, L., Alexandrie, A.K., Ambrosone, C., Autrup, H., Autrup, J.L., et al. (2001) Metabolic Gene Polymorphism Frequencies in Control Populations. Cancer Epidemiology, Biomarkers \& Prevention, 10, 1239-1248.

[61] Devlin, R.B., C.B. Smith, M.T. Schmitt, A.G. Rappold, A. Hinderliter, D. Graff, et al. (2014) Controlled Exposure of Humans with Metabolic Syndrome to Concentrated Ultrafine Ambient Particulate Matter Causes Cardiovascular Effects. Toxicological Sciences, 140, 61-72. http://dx.doi.org/10.1093/toxsci/kfu063

[62] Abdilla, N., Tormo, M.C., Fabia, M.J., Chaves, F.J., Saez, G. and Redon, J. (2007) Impact of the Components of Metabolic Syndrome on Oxidative Stress and Enzymatic Antioxidant Activity in Essential Hypertension. Journal of Human Hypertension, 21, 68-75. http://dx.doi.org/10.1038/sj.jhh.1002105

[63] WHO (2010) Global Recommendations on Physical Activity for Health. WHO Press, Genebra, 1-60.

[64] (2009) Part A: Executive Summary. Nutrition Reviews, 67, 114-120.

[65] Warburton, D.E., Charlesworth, S., Ivey, A., Nettlefold, L. and Bredin, S.S. (2010) A Systematic Review of the Evidence for Canada's Physical Activity Guidelines for Adults. International Journal of Behavioral Nutrition and Physical Activity, 7, 39. http://dx.doi.org/10.1186/1479-5868-7-39

[66] Rodgers, A., Ezzati, M., Vander Hoorn, S., Lopez, A.D., Lin, R.-B. and Murray, C.J.L. (2004) Distribution of Major Health Risks: Findings from the Global Burden of Disease Study. PLoS Medicine, 1, e27. http://dx.doi.org/10.1371/journal.pmed.0010027

[67] Lee, I.M., Shiroma, E.J., Lobelo, F., Puska, P., Blair, S.N. and Katzmarzyk, P.T. (2012) Effect of Physical Inactivity on Major Non-Communicable Diseases Worldwide: An Analysis of Burden of Disease and Life Expectancy. The Lancet, 380, 219-229. http://dx.doi.org/10.1016/S0140-6736(12)61031-9

[68] Yokota, T., Kinugawa, S., Yamato, M., Hirabayashi, K., Suga, T., Takada, S., et al. (2013) Systemic Oxidative Stress Is Associated with Lower Aerobic Capacity and Impaired Skeletal Muscle Energy Metabolism in Patients with Metabolic Syndrome. Diabetes Care, 36, 1341-1346. http://dx.doi.org/10.2337/dc12-1161

[69] Samjoo, I.A., Safdar, A., Hamadeh, M.J., Raha, S. and Tarnopolsky, M.A. (2013) The Effect of Endurance Exercise on Both Skeletal Muscle and Systemic Oxidative Stress in Previously Sedentary Obese Men. Nutrition \& Diabetes, 3, e88. http://dx.doi.org/10.1038/nutd.2013.30

[70] Strasser, B., Arvandi, M. and Siebert, U. (2012) Resistance Training, Visceral Obesity and Inflammatory Response: A Review of the Evidence. Obesity Reviews, 13, 578-591. http://dx.doi.org/10.1111/j.1467-789X.2012.00988.x

[71] Giles, L.V. and Koehle, M.S. (2014) The Health Effects of Exercising in Air Pollution. Sports Medicine, 44, $223-249$. http://dx.doi.org/10.1007/s40279-013-0108-z 
[72] Heck, T.G., Petry, M.R., Maslinkiewicz, A., Goettems-Fiorin, P.B., Ludwig, M.S., Saldiva, P.H.N., et al. (2014) Residual Oil Fly Ash (ROFA) Inhalation Promotes Lung and Heart Oxidative Stress without Hemodynamic Effects in Exercising Rats. Journal of Exercise Physiology online, 17, 78-89.

[73] Heck, T.G., Petry, M.R., Maslinkiewicz, A., Goettems-Fiorin, P.B., Ludwig, M.S., Saldiva, P.H.N., et al. (2014) Effects of Ambient Particles Inhalation on Lung Oxidative Stress Parameters in Exercising Rats. Journal of Exercise Physiology online, 17, 58-69.

[74] Radak, Z., Atalay, M., Jakus, J., Boldogh, I., Davies, K., Goto, S., et al. (2009) Exercise Improves Import of 8-Oxoguanine DNA Glycosylase into the Mitochondrial Matrix of Skeletal Muscle and Enhances the Relative Activity. Free Radical Biology and Medicine, 46, 238-243. http://dx.doi.org/10.1016/j.freeradbiomed.2008.10.022

[75] Lopez-Uriarte, P., Nogués, R., Saez, G., Bulló, M., Romeu, M., Masana, L., et al. (2010) Effect of Nut Consumption on Oxidative Stress and the Endothelial Function in Metabolic Syndrome. Clinical Nutrition, 29, 373-380. http://dx.doi.org/10.1016/j.clnu.2009.12.008

[76] Sabate, J., Oda, K. and Ros, E. (2010) Nut Consumption and Blood Lipid Levels: A Pooled Analysis of 25 Intervention Trials. Archives of Internal Medicine, 170, 821-827. http://dx.doi.org/10.1001/archinternmed.2010.79

[77] Bao, Y., Han, J., Hu, F.B., Giovannucci, E.L., Stampfer, M.J., Willett, W.C., et al. (2013) Association of Nut Consumption with Total and Cause-Specific Mortality. New England Journal of Medicine, 369, 2001-2011. http://dx.doi.org/10.1056/NEJMoa1307352

[78] Sedaghat, A., Shahbazian, H., Haidari, F., Payami, S.P., Jahanshahi, A. and Latifi, S.M. (2015) The Effect of Soy Nuts on Glycemic Control, Lipid Profile and Insulin-Resistance in Type 2 Diabetic Patients. Open Journal of Endocrine and Metabolic Diseases, 5, 1-7. http://dx.doi.org/10.4236/ojemd.2015.51001

[79] Reis, V.V.C., Coelho, G.M.O., Soares, E.A. and Pereira, A.F. (2014) Effect of Dietetic Intervention in Brazilian Postmenopausal Women with Metabolic Syndrome. Endocrinology \& Metabolic Syndrome, 3, 8.

[80] van Dijk, S.J., Feskens, E.J., Bos, M.B., Hoelen, D.W., Heijligenberg, R., Bromhaar, M.G., et al. (2009) A Saturated Fatty Acid-Rich Diet Induces an Obesity-Linked Proinflammatory Gene Expression Profile in Adipose Tissue of Subjects at Risk of Metabolic Syndrome. American Journal of Clinical Nutrition, 90, 1656-1664. http://dx.doi.org/10.3945/ajcn.2009.27792

[81] Venturini, D., Simao, A.N., Urbano, M.R. and Dichi, I. (2015) Effects of Extra Virgin Olive Oil and Fish Oil on Lipid Profile and Oxidative Stress in Patients with Metabolic Syndrome. Nutrition, 31, 834-840. http://dx.doi.org/10.1016/j.nut.2014.12.016

[82] Volek, J.S. and Feinman, R.D. (2005) Carbohydrate Restriction Improves the Features of Metabolic Syndrome. Metabolic Syndrome May Be Defined by the Response to Carbohydrate Restriction. Nutrition \& Metabolism, 2, 31. http://dx.doi.org/10.1186/1743-7075-2-31

[83] Esmaillzadeh, A., Kimiagar, M., Mehrabi, Y., Azadbakht, L., Hu, F.B. and Willett, W.C. (2007) Dietary Patterns, Insulin Resistance, and Prevalence of the Metabolic Syndrome in Women. The American Journal of Clinical Nutrition, 85, 910-918.

[84] Mitjavila, M.T., Fandos, M., Salas-Salvadó, J., Covas, M.-I., Borrego, S., Estruch, R., et al. (2013) The Mediterranean Diet Improves the Systemic Lipid and DNA Oxidative Damage in Metabolic Syndrome Individuals. A Randomized, Controlled, Trial. Clinical Nutrition, 32, 172-178. http://dx.doi.org/10.1016/j.clnu.2012.08.002

[85] Schroder, H., Fito, M., Estruch, R., Martinez-Gonzalez, M.A., Corella, D., Salas-Salvado, J., et al. (2011) A Short Screener Is Valid for Assessing Mediterranean Diet Adherence among Older Spanish Men and Women. Journal of Nutrition, 141, 1140-1145. http://dx.doi.org/10.3945/jn.110.135566

[86] Kumar, S.A., Magnusson, M., Ward, L.C., Paul, N.A. and Brown, L. (2015) A Green Algae Mixture of Scenedesmus and Schroederiella Attenuates Obesity-Linked Metabolic Syndrome in Rats. Nutrients, 7, 2771-2787. http://dx.doi.org/10.3390/nu7042771

[87] Poppitt, S.D., Keogh, G.F., Prentice, A.M., Williams, D.E., Sonnemans, H.M., Valk, E.E., et al. (2002) Long-Term Effects of Ad Libitum Low-Fat, High-Carbohydrate Diets on Body Weight and Serum Lipids in Overweight Subjects with Metabolic Syndrome. The American Journal of Clinical Nutrition, 75, 11-20. 